\title{
COVID-19 and child development: educational material for family members
}

Mirela de Oliveira Figueiredo 1

iD https://orcid.org/0000-0003-0101-0115

Ana Luiza Alegretti 2

(iD https://orcid.org/0000-0001-6764-5944

Lilian Magalhães 3

(iD https://orcid.org/0000-0003-3666-3685

\footnotetext{
1,3 Programa de Pós-Graduação em Terapia Ocupacional. Departamento de Terapia Ocupacional. Universidade Federal de São Carlos. Rodovia Washington Luís, km 235 SP-310. São Carlos, SP, Brasil. CEP 13565-905. E-mail: mirelafigueiredo@gmail.com

2 Department of Occupational Therapy. University of Texas Health Science Center at San Antonio. San Antonio, Texas, United States.
}

\begin{abstract}
Objectives: to describe methodological procedures, theoretical foundation, activities and guidelines that compose an educational material designed for family members with a focus on the development of babies and children from 0 to 5 years old during the pandemic period.

Methods: methodological research was applied to the preparation and validation of the educational material. The elaboration involved a literature review, graphic material creation and a validation by experts.

Results: the literature review provided materials and background on child development principles and forms of stimulation through the realization of child occupations. The stage of validation by specialists provided a greater degree of reliability regarding the potential to stimulate activities and adequacy of the written elements of the material.

Conclusions: the methods employed made it possible to develop, evaluate and improve the educational material, ensuring greater quality to guide and assist families in the daily stimulation of their children and in the management of occupational disruption. The material can also be useful for education and health professionals, support undergraduate education and/or university extension activities that focus on child development.
\end{abstract}

Key words Child development, Child health, Health education, COVID-19

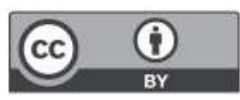




\section{Introduction}

Since the end of 2019, the coronavirus (COVID-19) pandemic, abruptly, imposed to people the experience of living under privation of occupational opportunities. Thus, a significant part of the population daily experience the loss of opportunity of access to education and job, buildings, libraries, public and recreational spaces, moving freely inside their own communities, travelling to other cities, states and/or countries. Such privation and losses were already experienced by disabled people, or people that live marginalized by poverty conditions, by racism among others. 1

Social isolation constitutes a global recommendation to COVID-19 infection ${ }^{2}$ and Occupational Therapy has the compromise of both supporting this recommendation and promoting awareness of how the interruption of daily occupations may affect physical, mental and occupational health, as well as conducting alternatives to manage this interruption. ${ }^{3}$

Specifically in relation to child population, the recommendation of social isolation paralyzed the attendance to schools, eliminated the coexistence with friend, locked parks, and cancelled cultural and sportive activities, interrupting usual ways of concretization of such occupations as studying, coexisting with relatives outside of the domestic nucleus, playing and leisure. Therefore, it is essential the awareness of how this interruption may affect mental and occupational health of people and why this occupations need to be resized, so that continuity of development and learning occur. ${ }^{3}$ Although, the family context needs to be considered while approaching measures for managing the interruption of typical childhood occupations.

Researchers have been demonstrated that resilience in face of a crisis is essential in facing it, and the style of coping based on what is needed to be done in face of a problem is associated with lower anxiety and health problems levels. ${ }^{4}$ Wilcock ${ }^{5}$ refers that it is impossible to imagine human life without doing, once people are constantly doing something with some personal purpose or for others. Historically, human evolution resulted from continuous and progressive actions that made possible the species to survive. 5 In accordance with what was done and/or how was done reverberated in stimulation, entertainment and health, or in depression, alienation and stress: "doing or not doing are powerful determinants of wellbeing or disease" (p.3). 5

Rodger and Zivian6 indicate that occupations provide a sense of purpose, act in time and space organization and constitute an alternative for development and expression of identity. Occupations have been classified as self-care, work/productivity or school, leisure or playing, and spirituality. The variations arises from what is typical for each age cycle, for example, work/productivity for adults and school and play for children. The way children see themselves and the world is directly associated with the roles they assume. As the child acquires roles such as student, brother/sister or a being that plays, occupies a position or status, he/she also acquires a social identity and obligations that are experimented and related by means of what and how he/she does.

Therefore, the occupations and occupational roles provide structure for children, being important that there is balance of engagement regarding occupations and their respective roles. The excessive engagement will reverberate in excessive demands, role conflicts, stress, boredom and demotivation, which can lead to occupational under-engagement. On the other hand, when an individual cannot perform the occupations and roles he/she desires, due to a disease, deficiency, deficits in skills and/or because of circumstantial conditions that impair or preclude, Rodger and Ziviani6 refer to a occupational and/or occupational roles disruption. Occupational therapists work with children whose occupations and occupational roles had been perturbed or interrupted. 6

Thibeault ${ }^{7}$ affirms that the process of rebuilding of life and promotion of wellbeing, after episodes of interruption of occupations, requires the awareness on both self-care and care for others; for the experience of feelings of belonging, connection, pleasure, hope, feeling of coherence, continuity, purpose and meaning; for the involvement in roles and occupations that are significant and valorized for each one individual.

Health professionals frequently provide educational materials to the target population of distinct interventions, although not necessarily had received specific guidance for the preparation of it. These educational materials provide to people the remembrance of information whenever it is needed, favor fixation and permanence of the message, have flexibility in access time and easy portability. 8

In the current COVID-19 pandemic, it is essential that the transfer of knowledge to the population about the best practices for the mitigation of the effects of social life privation occurs in a similar or faster pace than the aggravation of pandemic. It is known that the dissemination of traditional scientific publication in websites or electronically is slow, and social networks had accelerated this process. ${ }^{9}$ At the 
same time, educational material, besides having free access, needs to contain key-information in a clear and practical way. 9

Researches have been pointed at the existence of educational materials whose reading is hard, compromising comprehension and storage of information by people. 8 Besides the adequacy of writing style, the objective itself of the material needs to be evident so that the reader becomes interested and pays attention to the reading. Written materials that provides information on "how to do" are recommended for people are interested for and/or need information that help them in solving their problems and/or improve their own wellbeings. ${ }^{8}$

The present study, recognizing the ethical commitment of making accessible to the public scientific knowledge for relatives of children who suddenly suffered the interruption of their occupations due to COVID-19, provides an educational online material composed by activities and guidelines for relatives to perform with their children at home. The proposition of activities and guidelines constitute a resource for managing child occupations that ceased to be performed in their usual manner and for stimulation of the development of child population.

\section{Methods}

Methodological research, according to Polite and Beck10 definition "Methodological studies assess development, validation and evaluation of tools and research methods (p.330)". According to Polite and Beck10 "most of methodological studies are not experimental and frequently focused on the development of new instruments" 10 In the present study, the focus was on elaborating and validating an educational manual according to Echer's description. ${ }^{11}$ In this way, the material was elaborated in three stages: Stage 1: literature review for constituting theoretical foundation about child development and ways of stimulating this development by means of concretization of child occupations; Stage 2: graphic material creation; Step 3: validation of the material by specialists.

\section{Stage 1: Review and theoretical foundation}

The literature review was performed according to Grant and Booth. 12 This means an investigation of recent literature that does not involve terms and chronology parameters, for the replication of review is not predicted, but the collection of materials that are adequate to the investigated theme. The assessment occurred in websites of international and national associations of occupational therapy, in the World Health Organization website, in the Centers for Disease Control and Prevention website, in the Brazilian Ministry of Health website, in Scielo.org and Pubmed databases, besides Google Scholar.

The searches were performed by means of the terms "child development", "development milestones", "child stimulation", "child occupations". Of the material found, official documents, scientific articles and books that provided knowledge on principles and milestones in child development and about ways of stimulating development by means of concretization of child occupations. From this knowledge, activities and guidelines were defined and took part in the conception of the educational material

\section{Stage 2: graphic material creation}

The creation of graphic material occurred after defining activities and guidelines to be included in the educational material. Based on the literature found, the authors conceived a text production that was forwarded to a designer. The designer created the graphic material by means of typesetting and designing of the text. Typesetting consisted in the choice for type, size and color of the font used, line and paragraph spacing, limits of margins and the type of program to be used in the creation/edition and exhibition of the graphic presentation. The designing included, along with the typesetting, the visual planning of the communication to be expressed in the educational material, that is, the planning of the visual aesthetics the text should present once it acts as a discourse that lacks a specific language and a meaning network. ${ }^{13}$

\section{Stage 3: Validation of the material}

According to Echer, 11 the validation of manuals focused on healthcare should be executed in many stages of analysis, being the first one constituted by health professionals and professionals from related fields, specialized in the theme. In sequence, the process should be executed by possible users of the manual. The contribution of experts in the theme because they have knowledge, experience and interests that may differ, complement or question the perspective of the creators of the material - favors the creation of a material that meets the actual demands and expectations of the target public. Altogether, the stages make possible that the material becomes uniform and make health care practices official.11

The material described and elaborated in this 
article was analyzed by eight experts in the theme, from different professional categories, namely: four pedagogues that act in early childhood education, two occupational therapists that act in the infant rehabilitation field, a pedagogue that is a pedagogic coordinator of elementary and early childhood learning, a physical educator that is a teacher and coordinator in the physical education sector of a municipal secretary of education. The professionals had virtual access to the material and answered a questionnaire created in Google Forms. The questionnaire had a question regarding the potential of activities to stimulate infant development and other about the clearness of reading and description of activities.

Once the material was composed for activities grouped by months and years of life, the two questions of the questionnaire were made for each one of the age groups, being the answers distributed in a Likert scale, which corresponded to: 1. Totally disagree, 2. Disagree, 3. Neutral, 4. Agree and 5. Totally agree. Besides that, there was a field for the professional to justify his/her answers and give his/her opinion, criticism or suggestion. The professionals did not need to identify themselves, ensuring privacy for the expression of ideas.

\section{Results and Discussion}

Educational material, 14 presented in online format with thirteen colored pages, composed by text and illustration content. The theoretical foundation of the educational material, obtained through literature review, and that determined the selection of activities and guidelines refers to principles and milestones of child development and ways of stimulating child development in infants from 0 to 5 years, by means of concretization of child occupations.

Therefore, in order to elaborate the material, it was considered that child development constitutes a sequential process of neural and sensorial maturation, physical growth, acquisition of motor, cognitive, affective social and communication skills. Such process is started in intrauterine life and continues in postpartum, 15,16 being influenced by biological, environmental and socioeconomic factors. ${ }^{17}$ In this way, changes and acquisitions occur sequentially through time, comprehending development milestones. 18 These milestones can be observed in babies and children, constituting indicators for the follow up of each age cycle. 19

Papalia and Olds 18 refer the main milestones of typical motor and cognitive development milestones during the so called early childhood (0 to 3 years) and middle childhood (3 to 6 years). In addition, Rosa Neto ${ }^{20,21}$ presents child development by means of acquisitions related to fine motor skills, global motor skills, balance, body scheme, spatial organization, temporal organization and language. In Table 1, these milestones and acquisitions are synthetized, and have been used as referential to the selection and disposition of activities and guidelines of the educational material by age cycles.

In this way, activities and guidelines contained in the educational material are focused on the stimulation of motor and cognitive skills, according to development milestones as referred by Papalia and Olds 18 and "CDC's Developmental Milestones". 19 The activities proposed, in a higher or lower level, require fine and gross motor skills, body scheme, spatial organization, temporal organization and language, and due to this, may be stimulators of these skills and acquisitions, based on definition proposed by Rosa Neto20,21 and "Help ${ }^{\circledR}$... at Home 03". 22

Activities and guidelines contained in the material were, therefore, grouped in development stages and distributed in months and years of life, as presented in Table 2 .

The activities and guidelines of the educational material constitute ways of stimulating child development, whilst make possible that children in social isolation - in the current case confined at home amidst the pandemic - concretize typical occupations of their age, such as playing, studying and selfcare. Hence, the elaboration of educational material was also embedded in the promotion of: a) a secure and healthy environment for learning, growing and physical, cognitive and mental development; b) participation in typical activities for the age; c) development of skills that make possible the engagement in daily occupations and activities; d) health, of wellbeing and satisfaction in life, according to recommendations of the American Occupational Therapy Association 23 and Canadian Association of Occupational Therapists. 24 The entities propose the prevention or mitigation of occupational privation, understanding that, depending on the type of environment that a person lives, there may have some limitation to access and enjoyment of significant experiences that are favorable to personal development. 25,26

Finally, in relation to the stage of validation by experts, there were a unanimous agreement regarding the suggested activities are helpful in the stimulating the development of target population of the material, with some suggestions for a more didactic and impersonal writing. Suggestions were accepted, which generated the final version. 14 
Table 1

Milestones and acquisitions of Child development.

Development milestones

Early childhood (0 -3 years)

Middle childhood (3 - 6 years)
Head control: capability of turning the head for one side to another when laid in supine position and raising the head for seconds when laid in prone position since birth. From 2 to 3 months, the head is raised higher in order to maintain it erect when held or sat with support, with 4 months.

Hand control and fine motor skill: presence of reflex of grasping, which makes the hand to close when touched in the palm, it will cease to be involuntary around 3 months and a half, making possible to hold an object of moderate size, like a rattle. Around 6 months, starts to hold objects in one hand and place in the other.

Body control, global motor skills, balance and locomotion: the capability of deliberately turn occurs after 3 months, initially turning from prone to supine positions, to the reverse. At 6 months sits down without support and 10 months moving by him/herself, crawling in different manners, standing with support to stand alone with 11 months.

Cognitive, sensorial-perceptive, Emotional and Language.
A 1-month-old baby is capable of following a moving person with the eyes, at 3 months raises the arm to reach a hanging ring, at 6 months is interested for details in objects and at 12 months starts to imitate. At 26 months, combines 4 colors. Onset of development of body scheme as recognition of his/her own body.

Babies up to 6 months babble, at 9 months expressively chatter, with 14 and 16 months are capable of using 2 different words appropriately, after 20 months reproduce simple sentences with two words and know the name of up to three objects, at 32 months speak six to seven words and use preterit.

Spatial organization starts with the displacement of baby performed by the family associated with the discovering of hand/foot with the mouth, being enhanced while the baby sits and starts to experiment the space which is around him/her vertically and with liberation of upper limbs. After the child learns to locate him/herself in relation to objects, he/she starts to locate and place objects, at 2 years they are able to correctly place simple pieces of geometrical figures in their respective spaces in a table or toy.
Hand control and fine motor skill: at 3 years children are capable of building a bridge with blocks and holding a pencil. At 4 years, they place a line in a big hole and copy a circle. At 5 years, drawn straight lines following a model, solve mazes and paint without getting outside the drawn.

Body control, global motor skills, balance and locomotion: at 3 years, they will be able to lean the thorax frontwards and maintain corporal balance, to jump, take stairs without support and alternating feet. At 4 years, they will have a more effective control to stop, start and turn, jump higher, to go downstairs without support and stand on tiptoe. At 5 years, these skills become enhanced for higher jumps and distances, for example, jumping in one feet.

The children will have egocentrism, but will gradually comprehend other people's point of view, will develop illogical ideas about the world and events, memory and language will improve.

Improvement of body scheme represented by the acquisition of conscience that the body is constituted by parts/limbs, which each part of the body has a function and with this, there is possibility of action with the body and its parts.

Improvement of the orientation of the child in the space in relation to static objects/people and objects/people in movement. At 3 years, they identify which object is shorter or longer, with 4 years solve simple puzzles according to a model and at 5 years, identify right and left in themselves.

After 3 years, the children will be capable of numerical counting and at 4, to speak gradually more complex sentences, both in number of words and in meaning. 
Table 2

Activities and guidelines by age range.

Age range

Activities and guidelines

0 to 4 months

In order to develop cervical, visual and cognitive control, it is suggested that the baby is placed in prone and supine positions, for up to 4 minutes a few times per day. Adults may hold a toy in the height of the baby's eyes for, respectively, stimulate the rise of the head, visual fixation and attention. For fine motor coordination and handgrip, it is indicated to place one of the fingers in each one baby's hands, or soft and light toys, stimulating the baby to perform the grip movement. For cognitive and language stimulation, it is recommended to talk, sing, play and imitate the sounds of the baby.

4 to 9 months

Continuity of laying the baby in prone and supine positions, showing a toy at the height of the eyes, the toy should be moved to stimulate the baby to follow it visually, in vertical and horizontal ways, whilst cervical control is strengthened. Continue to offer toys for babies to hold and create movements for joining hands, to stimulate handgrip and bringing upper limbs to the middle line. Start the positioning of the baby in the vertical position with feet placed on the ground, stimulating coordination of lower limbs and global motor skill. Indication of hide and seek plays, reading of books with colorful figures, naming of figures and ways of inciting the baby to babble, for cognitive and language stimulation.

9 to 12 months

Continuity of laying the baby in prone or supine positions, being recommended that toys be placed out of reach, stimulating the baby to roll, besides the cervical control and visual following. It is indicated ways of clapping hands and sitting with support in order to stimulate global and fine motor coordination, the control of body and balance. For cognitive and language stimulation, we suggest the continuity of reading of books with illustrations, pointing at them, naming and describing them, and ways to incite the baby to verbalize.

1 year to 1 year and 6 months

1 year and six months to 2 years

2 years to 2 years and 6 months

2 years and 6 months to 3 years
Many options are provided to stimulate the fine motor skill, body scheme, cognition and language of the child, such as dawning with pencil or chalk; searching for toys by means of clues about size, color, format; while reading books asking the child to turn the pages, to reproduce sons from the illustrations and to try to verbalize what is being pointed; showing photos and naming familiar and significant people and places; to identify and name body parts at shower time, when dressing and during meals. It is recommended to motivate the execution of desired behaviors and a routine to sleep and prevent reluctances or night wakes.

For cognitive and fine motor coordination, it is recommended blocks to build towers; placing big beads or straws in a string; solving of puzzles of 4,6 up to 8 pieces with forms, colors, animals, fruits or transports; toys/objects for squeeze/pull/push/spin a button or handle; drawing and painting with wax chalk and thick pencils or with the fingers with gouache paint. For cognition and language, to maintain the indication of reading books every day, asking the children to speak the names of animals, colors, shapes, sizes and body parts. It is suggested to ask the children to help in simple tasks at home, with the recommendation of positive reinforcement for stimulating and maintaining good behaviors.

In order to stimulate global motor coordination and body scheme, it is indicated plays such as "Simon Says" with request of actions with body parts; of grabbing balls of different types and sizes; up and down steps. For cognitive and language stimulation, it is recommended, together with reading books, ask the children to describe details of figures/drawings; to teach the number/concept "one" using objects; to teach the concept of "me", "mine", "you" and "yours" by means of "who" questions. Fine motor coordination and handgrip can be stimulated with drawing and painting with wax chalk and pencil, training grip with the indicator and thumb fingers.

It is indicated, in order to stimulate fine motor skills and cognition, to draw lines and shapes; to color inside figures; stacking rings, boxes or blocks according to the size; put beads/big straws in a string. For stimulation of the cognition and language, it is indicated to continue reading books and pointing at figures, requesting to name and describe what is seen; to teach the concept of "two" using objects, to find identical colors and images; Pretend Play. For global motor coordination and balance, it is recommended to play with obstacles. 
Activities and guidelines by age range. book reading, with the addition of repetition of the words, by the children, after the familiar reads, and of counting with their own words what they see in the book. Altogether, to include in the conversations with children, requests for saying name, full name, mother/father/brother/sister's name, the use of pronouns "he" and "she", to think and explain "why" and "how" regarding things, to teach the opposites by means of objects/actions; classification of similar colors and images, although not identical. For global motor coordination and balance, it is recommended to play with balls while sat, using hands and/or feet, walking and overcoming a path with obstacles. The indication for fine motor coordinating and optimization of handgrip occurs by means of coloring pages and dot box games. to tell what happened in the story, to think and tell what can happen in new stories. For stimulation of temporal and spatial organization, cognition and motor coordination, it is suggested the creation of a calendar with the daily activities of a week; playing "Simon Says" in order to practice "inside, outside, low, high, unturned, turned, next, far"; puzzle and construction toys; drawing with pencil the first letters and human figures with 2 to 4 body parts.

\section{Final Considerations}

In the current COVID-19 pandemic, social media has been a resource for knowledge spreading, specifically in the dissemination of educational material for distinct populations and purposes. The present article exhibited the development of an educational material composed by suggestions of guidelines and activities to be executed by parents and their children, in the context of social isolation imposed by pandemic. Such activities and guidelines aim the continuity of the development of child skills and the concretization of occupations and occupational roles typical for the age. The elaboration of the material was based on the ethical commitment of making public a scientific knowledge for parents with children that suddenly experienced the interruption of their usual daily activities. The use of the material can be also expanded to health and education professionals that act in assistance and orientation to these parents. The present article makes possible to subside the learning process and university extension activities that aim child development, specifically in early and middle childhood.

The methodology adopted in the elaboration of the material followed diverse procedures. We used a literature review that propitiated that activities and guidelines were based in milestones and principles of child development and in ways of stimulating this development, considering the importance of making and occupations for human development and existence. The validation by experts provided a higher level of reliability regarding the potential of stimulation of activities and their quality and effectiveness. We conclude that the produced material, as a strategy of translation/transferal of knowledge, may contribute to the management of the abrupt interruption of child occupations, ensuring parents the access to guidelines and suggestion of activities that favor stimulation and continuity of the development of babies and children from 0 to 5 years.

Despite the cautions taken, we were not able to infer the evaluation of parents about the material. In the same way, only professionals from a specific region in the country were consulted, which impede us to assure cultural validity of the material within other contexts. Further studies should apply qualitative and quantitative methods of research to identify the usefulness of the material in diverse groups. We highlight that the suggested activities are not excluding, but suggested as occupational strategies, among many others, which can stimulate child development and make possible the concretization of typical occupations and occupational roles in childhood.

\section{Author's contribution}

Figueredo MO contributed with theoretical and methodological conception of the study, data collection, discussion and writing. Alegretti AL and Magalhães L contributed with theoretical and methodological basis and final review. All authors approved the final version of the article. 


\section{References}

1. Hammell KW. Engagement in living during the Covid-19 pandemic and ensuing occupational disruption. [Internet] 2020. [acesso 5 set 2020]. Disponível em:http://caot.ca/document/7179/Ensuring\%20occupational\%20disruption.pdf?fbclid=IwAR0Gocd3XIPpEME4 wbPrJ2CnsIuY_WzIBBt6NncdCYoDg14k8rAG6-cKEU

2. WHO (World Health Organization). Coronavirus disease (COVID-19) advice for the public. [Internet], 2020. [acesso 5 set 2020]. Disponível em: https://www.who.int/emergencies/diseases/novelcoronavirus2019/advice-for-public

3. Mynard L. Normal life has been disrupted. Managing the disruption caused by COVID-19. An Occupational Therapy Guide I. [Internet], [acesso 5 set 2020]. 2020. Disponível em: https://otaus.com.au/publicassets/af4690026f6aeal 19404005056be13b5/OT\%20Guid\%20COVID19\%20March\%202020.pdf?246d3087-7f6d-ea11-9404 005056be13b5

4. Summerfield D. The invention of post-traumatic stress disorder and the social usefulness of a psychiatric category. Brit Med J. 2001; 322: 95-8.

5. Wilcock AA. Occupation for Health. Brit J Occup Ther 1998; 61(8): 340-5

6. Rodger S, Ziviani J. Children, their environments, roles and occupations in contemporary society. In: S Rodger, J Ziviani. Occupational therapy with children: understanding children's occupations and enabling participation. Oxford, UK: Blackwell Publishing; 2006. p. 3-18.

7. Thibeault R. Occupation and the rebuilding of civil society: notes from the war zone. Journal of Occupational Science. 2002; 9: 38-47.

8. Hoffmann T, Worrall L. Designing effective written health education materials: Considerations for health professionals. Disabil Rehabil. 2004; 26 (19): 1166-73.

9. Chan A, Nickson CP, Rudolph JW, Lee A, Joynt GM. Social media for rapid knowledge dissemination: early experience from the COVID-19 pandemic. Anaesthesia. 2020; 75(12): 1579-82.

10. Polit DF, Beck CT. Tipos específicos de pesquisa. In: Polit DF, Beck CT. Fundamentos de pesquisa em enfermagem: avaliação de evidências para a prática de enfermagem. 7 ed. Porto Alegre, RS: Artmed; 2011. p. 316-38.

11. Echer IC. Elaboração de manuais de orientação para o cuidado em saúde. Rev Latino-Am Enferm. 2005;13(5): 754-7.

12. Grant MJ, Booth A. A typology of reviews: an analysis of 14 review types and associated methodologies. Health Information \& Libraries Journal. 2009; 26: 91-108.

13. Souza Â, Pellanda LC. A diagramação de textos científicos tornou-se uma atividade secundária? Rev HCPA. 2010; 30 (2): 196-197.

Received on October 15, 2020

Approved on November 25, 2020
14. Figueiredo MO, Alegretti AL. Atividades para familiares realizarem com os filhos em casa. São Carlos: UFSCar/CPOI， 2020. ISBN: 978-65-86558-04-3. Disponível em: http://www.sibi.ufscar.br/arquivos/atividades-para-familiares-realizarem-com-os-filhos-emcasa.pdf

15. Noer C, Halpern R. O pediatra e a promoção do desenvolvimento infantil: otimizando a consulta. Residência Pediátrica.2018; 8(3): 156- 162.

16. Silk JS, Redcay E, Fox, NA. Contributions of social and affective neuroscience to our understanding of typical and atypical development. Dev Cogn Neurosci. 2014; 8: 1-6.

17. Amorin RCA, Laurentino GEC, Barros KMFT, Ferreira, ALPR, Moura Filho AG, Raposo MCF. Programa de saúde da família: proposta para identificação de fatores de risco para o desenvolvimento neuropsicomotor. Rev Bras Fisioter. 2009;13(6): 506-13.

18. Papalia DE, Olds SW, Feldman RD. Desenvolvimento Humano. 8 ed. Porto Alegre: ARTMED Editora S.A; 2006.

19. CDC (Centers For Disease Control And Prevention). Learn the Signs. Act Early. [Internet], 2020.[acesso 5 set 2020]. Disponível em: https://www.cdc.gov/ncbddd/actearly/ index.html?CDC_AA_refVal $=$ https $\% 3 \mathrm{~A} \% 2 \mathrm{~F} \% 2 \mathrm{Fwww} . \mathrm{cdc}$ .gov\%2Factearly\%2Findex.html

20. Rosa Neto F. Manual de avaliação motora. Porto Alegre: Artmed; 2002.

21. Rosa Neto F. Manual de avaliação motora: intervenção na educação infantil, ensino fundamental e educação especial. 3 ed. rev. Florianópolis: DIOESC; 2015.

22. Warshaw SP. HelpV́... at Home 0-3. Developmental Support and Information. Handouts for Families with Infants and Toddlers Birth to Three. (2 ed.). Palo Alto, CA: Vort Corporation; 2006.

23. American Occupational Therapy Association. Estrutura da prática da Terapia Ocupacional: domínio e processo - $3^{\mathrm{a}}$ ed. traduzida. Revista de Terapia Ocupacional da Universidade de São Paulo. 2015; 26 (esp): 1-49.

24. Canadian Association of Occupational Therapists. Enabling occupation: An occupational therapy perspective (Rev. ed.). Ottawa, ON: CAOT Publications ACE; 2002.

25. Occupational Therapy Australia. Position Paper: Occupational deprivation. [Internet], 2016. [acesso 5 set 2020]. Disponível em: https://otaus.com.au/publicassets/ 5e5829df2503e911a2c2b75c2fd918c5/Occupational\%20De privation\%20(April\%202016).pdf

26. Whiteford G. Occupational Deprivation: Global Challenge in the New Millennium. Brit J Occup Ther. 2000; 63 (5): 200-4. 